\title{
Filoviruses Infect Rhesus Macaque Synoviocytes in Vivo and Primary Human Synoviocytes in Vitro
}

Timothy K. Cooper, * James Logue, * David X. Liu, * Donna L. Perry, ${ }^{*}$ Randy J. Hart, * Amanda M.W. Hischak, * John G. Bernbaum, * Dawn M. Gerhardt, ${ }^{*}$ Oscar Rojas, ${ }^{*}$ J. Kyle Bohannon, ${ }^{*}$ Katie R. Hagen, ${ }^{*}$ Reed F. Johnson, ${ }^{\dagger}$ Ian Crozier, Peter B. Jahrling, * Lisa E. Hensley, ${ }^{*}$ and Richard S. Bennett*

Accepted for publication

May 8, 2020.

Address correspondence to Timothy K. Cooper, D.V.M., Ph.D., Division of Clinical Research, National Institute of Allergy and Infectious Diseases Integrated Research Facility, Fort Detrick, 8200 Research Plaza, Frederick, MD 21702; or Lisa E. Hensley, Ph.D., M.S.P.H., Division of Clinical Research, Integrated Research Facility at Fort Detrick, National Institute of Allergy and Infectious Diseases, National Institutes of Health, Fort Detrick, B-8200 Research Plaza, Frederick, MD 21702. E-mail: timothy.cooper@nih.gov or lisa.hensley@nih.gov.

\begin{abstract}
The most commonly reported symptom of post-Ebola virus disease syndrome in survivors is arthralgia, yet involvement of the joints in acute or convalescent Ebola virus infection is not well characterized in human patients or animal models. Through immunohistochemistry, we found that the lining synovial intima of the stifle (knee) is a target for acute infection by Ebola virus/Kikwit, Ebola virus/Makona-C05, and Marburg virus/Angola in the rhesus macaque model. Furthermore, histologic analysis, immunohistochemistry, RNAscope in situ hybridization, and transmission electron microscopy showed that synoviocytes of the stifle, shoulder, and hip are a target for mouse-adapted Ebola virus/YambukuMayinga infection during acute disease in rhesus macaques. A time course of infection study with Ebola virus/Kikwit found that the large joint synovium became immunopositive beginning on postinfection day 6 . In total, the synovium of 28 of 30 rhesus macaques with terminal filovirus disease had evidence of infection (64 of 96 joints examined). On the basis of immunofluorescence, infected cell types included $\mathrm{CD}^{+} 8^{+}$type A (macrophage-like) synoviocytes and $\mathrm{CD} 44^{+}$type B (fibroblast-like) synoviocytes. Cultured primary human fibroblast-like synoviocytes were permissive to infection with Ebola and Marburg viruses in vitro. Because synovial joints include immune privileged sites, these findings are significant for future investigations of filovirus pathogenesis and persistence as well as arthralgias in acute and convalescent filovirus disease. (Am J Pathol 2020, 190: 1867-1880; https://doi.org/ 10.1016/j.ajpath.2020.05.013)
\end{abstract}

Filovirus disease (FVD) encompasses a clinical disease syndrome caused by members of the Filoviridae family, including Ebola virus (EBOV) and Marburg virus (MARV). ${ }^{1}$ Initial FVD outbreaks were small and often had high case fatality rates, resulting in only a small number of survivors. After recovery from acute disease, arthralgia has often been reported, but the significance of this sequela was largely overlooked until the 2013-2016 Western African Ebola virus disease (EVD) outbreak, which produced far more survivors than all previous outbreaks combined.

\footnotetext{
Supported by US National Institute of Allergy and Infectious Diseases Contract HHSN272200700016I (Battelle Memorial Institute); NIH Interagency Agreement NOR15003-001-00000; and federal funds from the National Cancer Institute, NIH, under Contract No. HHSN261201500003I, Task Order No. HHSN26100043 and Contract No. 75N91019D00024, Task Order No. 75N91019F00130 (IC).

Disclosures: None declared.

The content of this publication does not necessarily reflect the views or policies of the US Department of Health and Human Services or of the institutions and companies affiliated with the authors, nor does mention of trade names, commercial products, or organizations imply endorsement by the U.S. Government.
} 
Joint pain is a common symptom during acute EVD, reported in up to $74 \%$ of patients compared with only up to $4 \%$ in close household contacts. $^{2-5}$ After recovery, arthralgia is among the most commonly reported symptoms in EVD survivors. ${ }^{5-11}$ In the largest controlled study to date, joint pain was reported in $47.5 \%$ of Liberian EVD survivors (versus only $17.5 \%$ of controls). ${ }^{12}$ Although not characterized in fine detail, arthralgia in survivors is generally reported to be polyarticular and symmetrical without effusion, redness, or reduced range of motion (ie, mechanical or noninflammatory in nature) and predominantly affects large joints. ${ }^{7,13}$ In the single published study that identified specific affected joints, knees were most commonly represented. ${ }^{11}$ Arthritis with inflammatory characteristics, including joint effusion, early morning stiffness improving with activity, and corticosteroid responsiveness, has rarely been reported. ${ }^{12,14,15}$ Arthralgia may persist for more than 2 years after infection, ${ }^{16}$ and impaired functional recovery attributable to arthralgia may have significant economic and quality-of-life effects. ${ }^{6}$ Arthralgia has similarly been reported as a typical clinical sign of Marburg virus disease, although in even less detail. ${ }^{17,18}$

In challenging care settings and in the context of severe acute illness in which joint involvement does not appear to contribute to severe morbidity or death, characterization of the phenotype or mechanisms of joint pain in acute or chronic disease has been limited or nonexistent: only a single published prospective study specifically included rheumatologic examinations of human EVD survivors. ${ }^{7}$ No laboratory or imaging evaluations were included in that study. In addition, because the articular cartilage is an immune privileged site, the possibility of viral persistence in synovial joints is a significant potential concern. ${ }^{19,20}$ Although a number of studies have looked for the persistence of EBOV in various body fluids of survivors (reviewed by Vetter et $\mathrm{al}^{21}$ ), only a single published case report has examined joint fluid in an EVD survivor with polyarthritis (from a single joint, negative by real-time RTPCR on day 34 of illness). ${ }^{15}$ To date, no studies have been published on the pathology of joints in natural or experimental acute or convalescent FVD, and the cause of arthralgia, either virus induced or autoimmune, remains unknown.

The synovium of diarthrotic joints is composed of two layers, a lining intima and a deeper subjacent subintima, with no intervening basement membrane. ${ }^{22-24}$ The synovial intima consists of three distinct cell types. Type A synoviocytes are resident phagocytotic bone marrow-derived macrophages and are immunolabeled for a number of markers, including CD68 (macrosialin), CD11b (integrin$\alpha \mathrm{M}$ ), CD163 (scavenger receptor cysteine-rich type 1 protein M130), immunoglobulin receptor Fc $\gamma$ RIIIa, and major histocompatibility complex class II. ${ }^{23,25}$ Type B synoviocytes are locally derived fibroblast-like cells with synthetic activity (including hyaluronic acid) and can be identified by positive staining for an enzyme necessary for hyaluronic acid synthesis, UDP-glucose 6-dehydrogenase, as well as CD44, vimentin, CD55 (complement decay-accelerating factor), CD90 (Thy-1 membrane glycoprotein), vascular cell adhesion molecule 1, intercellular adhesion model 1, and cadherin-11. Type B (fibroblast-like) synoviocytes play a critical role in the pathogenesis of rheumatoid arthritis, including antigen presentation and modulation of B- and T-cell responses. ${ }^{26}$ These two cell types are present in roughly equal numbers in healthy tissues. There is, additionally, a third, less common cell type, the mesenchymal stem cell, which expresses CD105 (endoglin). ${ }^{22,27}$ Synovial fluid is a dialysate of plasma from synovial capillaries modified with hyaluronic acid, lubricin (proteoglycan 4), and proteins produced by synoviocytes to provide support (and lubrication) to the avascular articular hyaline cartilage. Both macrophages and fibroblasts are well-described targets of filovirus infection within other tissues. ${ }^{28-31}$

In this study, synovium from the stifle joints of rhesus macaques acutely infected with wild-type EBOV Kikwit (EBOV/Kik), EBOV Makona-C05 (EBOV/Mak), and MARV Angola (MARV/Ang) was examined, and frequent staining of intimal synoviocytes for viral antigens by immunohistochemistry (IHC) was observed. Furthermore, we recently repeated the experiment originally described by Bray et $\mathrm{al}^{32}$ using mouse-adapted EBOV/YambukuMayinga (ma-EBOV/Yam) with rhesus macaques and completed a more extensive survey of EBOV infection of synovial tissues and fluids during acute disease to correlate with and better characterize rheumatic sequelae in survivors. Consistent with observations of other filoviruses, maEBOV/Yam replicates in large joint synovium during acute infection as demonstrated by IHC, in situ hybridization (ISH), and transmission electron microscopy (TEM), and high concentrations of EBOV genomic material are present in the synovial fluids. We found that both type A and type B synoviocytes are targets of filovirus infection during acute disease in the rhesus macaque model and that human primary synovial fibroblasts were also permissive to filovirus infection in vitro. Infection of the synovium during the acute disease may be a critical first step in the development of FVD-associated arthralgia in humans.

\section{Materials and Methods}

\section{Animals and Viruses}

Rhesus macaques (Macaca mulatta) were screened for antifilovirus antibodies, cleared by staff veterinarians, and acclimatized to the Maximum Containment (Biosafety Level 4) Laboratory at the Division of Clinical Research, Integrated Research Facility at Fort Detrick, National Institute of Allergy and Infectious Diseases, NIH before study assignment. Six Chinese-origin rhesus macaques received a 1000-plaque forming unit (PFU) target dose of EBOV/Kik by i.m. exposure for a model characterization study. Five Indian-origin rhesus macaques received a 
1000-PFU target dose of MARV/Ang by i.m. exposure. These five animals were controls for a vaccine study and had been vaccinated with RabAvert rabies vaccine before virus exposure. Five untreated Indian-origin rhesus macaques received a target dose of $1000 \mathrm{PFU}$ of EBOV/Mak by i.m. exposure as a rechallenge dose. Twelve Chineseorigin rhesus macaques received a 5000-PFU target dose of ma-EBOV/Yam by i.m. exposure. An additional 18 Chinese-origin rhesus macaques received a 1000-PFU target dose of EBOV/Kik by i.m. exposure for a disease time course [natural history (nh)] study. All animals used in this research project were cared for and used humanely according to the following policies: the Public Health Service Policy on Humane Care and Use of Animals, ${ }^{33}$ the Guide for the Care and Use of Laboratory Animals, ${ }^{34}$ and the US Government Principles for Utilization and Care of Vertebrate Animals Used in Testing, Research, and Training. ${ }^{35}$ All NIAID-IRF animal facilities and the animal program are accredited by the Association for Assessment and Accreditation of Laboratory Animal Care International.

All work with infectious virus was conducted in a Maximum Containment (Biosafety Level 4) Laboratory at the Division of Clinical Research, Integrated Research Facility at Fort Detrick, National Institute of Allergy and Infectious Diseases, NIH. EBOV/Kik (Ebola virus/Homo sapiens-tcCOD/1995/Kikwit-9510621) was obtained from BEI Resources (Manassas, VA) and diluted to a target dose of 1000 $\mathrm{PFU} / \mathrm{mL}$ before inoculation; actual inoculum virus titer was determined to be $8.67 \times 10^{2}$ for the model characterization study and $1.80 \times 10^{3}, 1.09 \times 10^{3}$, and $1.29 \times 10^{3}$ for the natural history study (infected in three separate challenges). MARV/Angola (Marburg virus/H. sapiens-tc/AGO/2005/ Ang-1379v, biosample SAMN05916381) inoculum was diluted to a target dose of $1000 \mathrm{PFU} / \mathrm{mL}$ before inoculation; actual inoculum virus titer was determined to be $1.67 \times 10^{3}$ $\mathrm{PFU} / \mathrm{mL}$. EBOV/Makona-C05 (Ebola virus/H. sapiens-tc/ GIN/2014/Makona-C05, biosample SAMN04490241) inoculum was diluted to a target dose of $1000 \mathrm{PFU} / \mathrm{mL}$ before inoculation; actual inoculum virus titer was determined to be $3.99 \times 10^{3} \mathrm{PFU} / \mathrm{mL}$. Mouse-adapted EBOV (Ebola virus/ USAMRIID/BALBc-lab/COD/1976/Yambuku-MayingaMA, biosample SAMN05859944) was obtained from Dr. Anthony Griffiths (Texas Biomedical Research Institute, San Antonio, TX). Virus inoculum was diluted to a target dose of $5000 \mathrm{PFU} / \mathrm{mL}$ before i.m. inoculation. The virus inoculum titer was $2.48 \times 10^{3} \mathrm{PFU} / \mathrm{mL}$ and $1.81 \times 10^{3}$ PFU/mL by Vero E6 plaque assay for study cohort 1 $(n=6)$ and study cohort $2(n=6)$, respectively.

All macaques were humanely euthanatized in accordance with predefined experimental end points, and gross necropsy was performed. For macaques infected with EBOV/Kik (model characterization) or EBOV/Mak, bilateral samples of stifle synovium were collected for histologic analysis. Macaques infected with MARV/Ang had only the right stifle synovium collected for histologic analysis. In the first cohort of macaques succumbing to
ma-EBOV/Yam, samples of synovium and meniscus from the right stifle only were collected for histologic analysis, and the same joint was swabbed for virus titer. For all animals in the second cohort as well as survivors from the first cohort, samples for virus titer, histologic analysis, and TEM were collected from both stifles. Additional synovial membrane samples for histologic analysis were also collected from hips and shoulders bilaterally. Macaques receiving EBOV/Kik for the natural history study had histologic samples collected bilaterally from the stifles, hips, and shoulders. Methods for histologic analysis, TEM, MARV ISH, and EBOV and MARV IHC have been previously described. ${ }^{31,36}$

\section{ISH}

To detect EBOV RNA in formalin-fixed, paraffin-embedded tissues, ISH was performed using the RNAscope $2.5 \mathrm{HD}$ RED kit (Advanced Cell Diagnostics, Newark, CA) according to the manufacturer's instructions. Briefly, $20 \mathrm{ZZ}$ probe pairs targeting the genomic EBOV VP4O gene were designed and synthesized by Advanced Cell Diagnostics (catalog number 507141). Replicative intermediate (antigenome) probes targeting the VP35 gene were used (catalog number 527491). Staining was performed as previously described. ${ }^{31}$

\section{Immunofluorescence}

Formalin-fixed, paraffin-embedded tissue sections were deparaffinized and rehydrated through a series of graded ethanol. Antigen retrieval was performed using Diva Decloaker citrate buffer (Biocare Medical, Pacheco, CA) for 30 minutes at $95^{\circ} \mathrm{C}$. After rinses with Tris-buffered saline with Tween (TBST), Background Sniper (Biocare Medical) was applied for 30 minutes. For CD68/EBOV-GP double stains, sections were then incubated with rabbit anti-EBOVGP (catalog number 0301-015; IBT Bioservices, Rockville, MD) or rabbit polyclonal IgG isotype control (catalog number ab27478; Abcam, Cambridge, MA) antibodies or plain diluent for 20 hours at $4^{\circ} \mathrm{C}$. After rinses with TBST, the sections were incubated with secondary Alexa Fluor 488-conjugated goat anti-rabbit antibody for 1 hour at room temperature. The sections were rinsed with TBST, and the Background Sniper was applied for 30 minutes. The sections were then incubated with mouse anti-CD68 (cata$\log$ number NBP-74570; Novus Biologicals, Centennial, $\mathrm{CO}$ ), normal mouse $\mathrm{IgG}$ isotype control antibody (catalog number ab18443; Abcam,), or plain diluent for 1 hour at room temperature. After rinses with TBST, the sections were incubated with secondary Alexa Fluor 594-conjugated donkey anti-mouse antibody for 1 hour at room temperature. For CD44/EBOV-GP double stains, sections were then incubated with rabbit anti-EBOV-GP (catalog number 0301-015; IBT Bioservices) or rabbit polyclonal IgG isotype control (catalog number ab27478; 

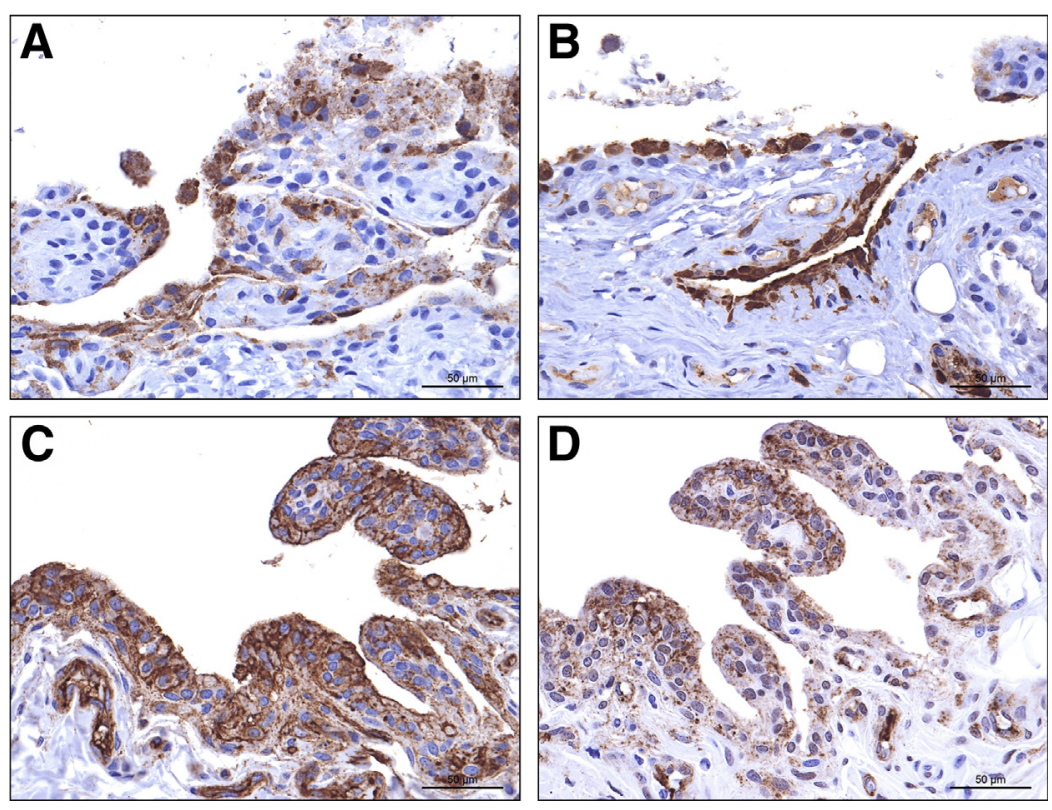

Figure 1 Immunohistochemistry shows viral targeting of stifle joint synoviocytes in rhesus macaques infected with filoviruses. Positive immunostaining results for Ebola virus (EBOV) glycoprotein (GP) (A) and EBOV matrix protein VP40 (B) in intimal synoviocytes from the stifle of an EBOV/Kikwit-infected Chinese-origin rhesus macaque. Synovial space is oriented at the top. Positive immunostaining results for Marburg virus (MARV) GP (C) and MARV matrix protein VP40 (D) in intimal synoviocytes from the stifle of a MARV/Angola-infected Indian-origin rhesus macaque. 3,3'-Diaminobenzidine chromogen with hematoxylin counterstain. Scale bars $=50 \mu \mathrm{m}$.
Abcam) antibodies or plain diluent for 20 hours at $4^{\circ} \mathrm{C}$. After rinses with TBST, the sections were incubated with secondary Alexa Fluor 488-conjugated donkey anti-rabbit antibody for 1 hour at room temperature. The sections were rinsed with TBST, and the Background Sniper was applied for 30 minutes. The sections were then incubated with mouse anti-CD44 (catalog number MA5-13890; clone 1563C11, Thermo Fisher, Waltham, MA), normal mouse IgG isotype control antibody (catalog number ab18443; Abcam), or plain diluent for 20 hours at $4^{\circ} \mathrm{C}$. After rinses with TBST, the sections were incubated with secondary Alexa Fluor 594-conjugated donkey anti-mouse antibody for 1 hour at room temperature. Autofluorescence was blocked using TruView autofluorescence blocker (Vector Laboratories, Burlingame, CA) for 5 minutes. Sections were cover slipped using the Vectashield hard set mounting medium with DAPI (Vector Laboratories). All fluorescent images were obtained using a Leica SP5 TCS-2 confocal microscope and Leica Application Suite Advance Fluorescence version 2.7.2.9586 (Leica Camera AG, Wetzlar, Germany).

\section{Quantitative RT-PCR from Stifle Swabs}

At necropsy, joint fluid was collected using a dry swab, which was then placed in $1 \mathrm{~mL}$ of virus transport collection buffer, inactivated by TRIzol LS (Ambion by Life Technologies, Austin, TX), and frozen at $-80^{\circ} \mathrm{C}$ for no longer that 90 days before RNA isolation and titering. Total RNA was isolated as described previously. ${ }^{37}$ Briefly, $70 \mu \mathrm{L}$ of sample inactivated by Trizol LS was added to $280 \mu \mathrm{L}$ of buffer AVL (Qiagen, Germantown, MD) with carrier RNA. Samples were then extracted using the QIAamp Viral RNA Mini Kit (Qiagen) in accordance with the manufacturer's instructions, eluted in $70 \mu \mathrm{L}$ of buffer AVE (Qiagen), aliquoted, and frozen. Viral RNA titer was determined using an experimental Critical Reagents Program EZ1 RT-qPCR kit assay (BEI Resources) in accordance with the manufacturer's instructions. Sample titers were reported as viral RNA copies per milliliter of sample.

\section{Cell Culture}

Primary human fibroblast-like synoviocytes (HFLS; Cell Applications Inc., San Diego, CA) were cultured in growth medium (catalog number 415-500). Human hepatocellular carcinoma (Huh-7) cells obtained from Dr. Yoshimi Tsuda (Research Institute for Microbial Diseases, Osaka University, Osaka, Japan) were cultured in Dulbecco's modified Eagle's medium with L-glutamine (Lonza 12-604Q, Williamsport, PA) supplemented with $10 \%$ heat-inactivated fetal bovine serum (Gibco, Thermo Fisher Scientific, Waltham, MA) and incubated at $37^{\circ} \mathrm{C}$ in $5 \%$ carbon dioxide as previously described. ${ }^{38}$ HFLS and Huh-7 cells were grown for 24 hours in T75 flasks, after which media was removed and replaced with $3 \mathrm{~mL}$ of media that contained diluted EBOV/Kik, EBOV/Mak, ma-EBOV/Yam, and MARV/Ang stocks used in nonhuman primate (NHP) studies (multiplicity of infection, 0.01 PFU/cell). Infections were performed in triplicate. Virus was incubated with the cells for 1 hour with rocking every 15 minutes to allow for viral attachment. After the initial incubation, the media was removed, cell monolayers were washed once with sterile phosphate-buffered saline, and media were replaced with 30 $\mathrm{mL}$ of growth media. The development of a cytopathic effect (CPE) was monitored by light microscopy and photographs were taken. Samples of $1 \mathrm{~mL}$ were collected daily from each flask starting after the addition of growth media 

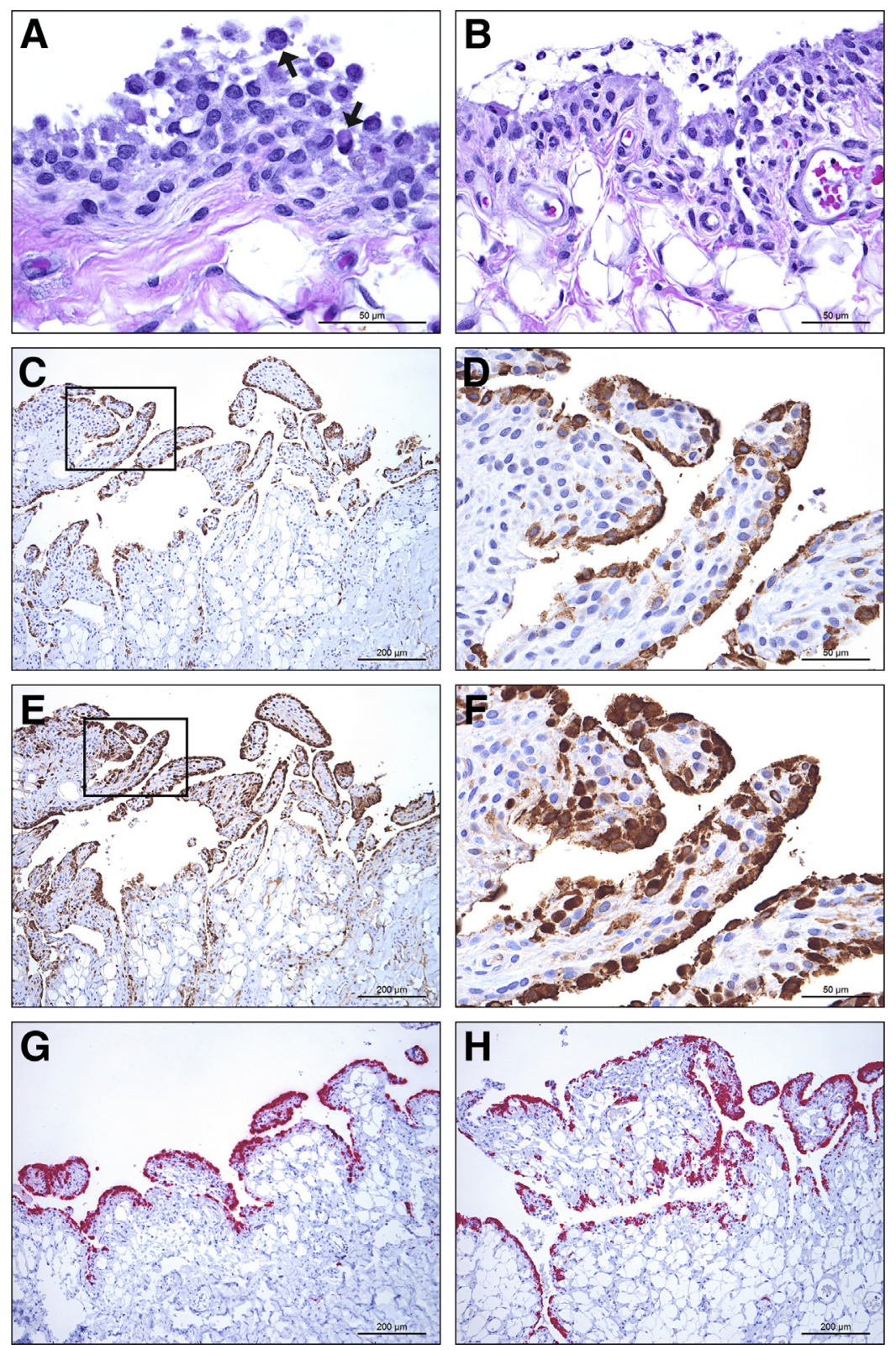

Figure 2 Histologic analysis, immunohistochemistry, and in situ hybridization show viral targeting of synoviocytes in rhesus macaques infected with mouse-adapted Ebola virus (EBOV)/Yambuku-Mayinga (ma-EBOV/Yam). A: Histologic analysis of the right stifle of nonhuman primate (NHP) 6 shows occasional degeneration and intracytoplasmic viral inclusion bodies (arrows) in intimal synoviocytes. B: Histologic analysis of the left stifle of NHP 5 shows mild acute inflammation, including viable and degenerate macrophages and neutrophils in the intima and synovial space. C-F: There is nearly diffuse immunolabelling of intimal synoviocytes for EBOV glycoprotein (C) and EBOV matrix protein VP40 (E) in the left shoulder of NHP 7. Boxed areas in $\mathbf{C}$ and $\mathbf{E}$ are shown at higher magnification in $\mathbf{D}$ and $\mathbf{F}$, respectively. $\mathbf{G}$ and $\mathbf{H}$ : There is nearly diffuse positive in situ hybridization of intimal synoviocytes for EBOV genome in the left shoulder of NHP 7 (G) and for EBOV replicative intermediate (antigenome) in the left stifle of NHP 5 (H). Hematoxylin and eosin (A and $\mathbf{B}), 3,3^{\prime}$-diaminobenzidine chromogen with hematoxylin counterstain $(\mathbf{C}-\mathbf{F})$, and red substrate chromogen with hematoxylin counterstain ( $\mathbf{G}$ and $\mathbf{H}$ ). Scale bars: $50 \mu \mathrm{m}(\mathbf{A}, \mathbf{B}, \mathbf{D}$, and F); $200 \mu \mathrm{m}$ (C, E, $\mathbf{G}$, and $\mathbf{H})$. (day 0) through to day 7 . The samples were stored at $-80^{\circ} \mathrm{C}$ until titered by plaque assay.

Additional flasks of HFLSs were infected with 1 PFU/cell and harvested on day 7 for MARV/Ang and day 8 for EBOV/Kik for TEM analysis. For conventional thin-section microscopic evaluation, cells were collected from flasks and preserved in $2.5 \%$ glutaraldehyde (E.M. Sciences, Warrington, PA) in Millonig's sodium phosphate buffer (Tousimis Research, Rockville, MD). After fixation was complete, the cells were washed repeatedly in Millonig's buffer and incubated for 2 hours in $1.0 \%$ osmium tetroxide in the same buffer. After rinsing steps in ultrapure water and en bloc staining with $2.0 \%$ uranyl acetate, the samples were dehydrated in a series of graded ethanols and infiltrated and embedded in Spurr's plastic resin (E.M. Sciences).
Embedded blocks were sectioned using a Leica UC7 U1tramicrotome (Leica Camera AG). Then 70- to 80-nm sections were collected on 200 mesh copper grids and poststained with Reynold's lead citrate. Samples were examined in a FEI Tecnai Spirit Twin transmission electron microscope, operating at $80 \mathrm{kV}$.

HFLS and Huh-7 cells were grown for 24 hours on 4-chambered slides (catalog number 30104; ABC Scientific, Glendale, CA), after which media was removed and replaced with $1 \mathrm{~mL}$ of media that contained diluted EBOV/Kik, maEBOV/Yam, EBOV/Mak, or MARV/Ang at a multiplicity of infection of 1 or with cell culture media (mock-infected negative control) and incubated at $37^{\circ} \mathrm{C}$ at $5 \%$ carbon dioxide. After incubation, slides were fixed with $1 \mathrm{~mL}$ of $20 \%$ neutral buffered formalin on day 4 for Huh-7 infections and 
Table 1 Summary of Joint Findings in Rhesus Macaques Acutely Infected with Mouse-Adapted EBOV/Yambuku-Mayinga

\begin{tabular}{|c|c|c|c|c|c|c|}
\hline \multirow{2}{*}{$\begin{array}{l}\text { Animal } \\
\text { no. }\end{array}$} & \multicolumn{2}{|l|}{ Stifle } & \multicolumn{2}{|l|}{ Shoulder } & \multicolumn{2}{|l|}{ Hip } \\
\hline & Left & Right & Left & Right & Left & Right \\
\hline NHP 1 & NE & $\begin{array}{l}\text { Synovial ICIB } \\
\mathrm{IHC}^{+}\end{array}$ & NE & & & \\
\hline NHP 2 & & $\begin{array}{l}\text { Synovial ICIB, } \\
\text { degeneration, and } \\
\text { inflammation } \\
\mathrm{IHC}^{+}, \mathrm{gISH}^{+}, \mathrm{riSH}^{+}\end{array}$ & & & & \\
\hline NHP 4 & $\begin{array}{l}\text { Synovial ICIB, } \\
\text { degeneration, and } \\
\text { inflammation, } \\
\mathrm{IHC}^{+}, \mathrm{gISH}^{+}, \\
\text {riISH }^{+}\end{array}$ & $\begin{array}{l}\text { Synovial ICIB, } \\
\text { degeneration, and } \\
\text { inflammation; } \\
\text { IHC }^{+}\end{array}$ & NSF; $\mathrm{IHC}^{+}$ & $\mathrm{NSF} ; \mathrm{IHC}^{-}$ & NSF; IHC ${ }^{-}$ & $\begin{array}{l}\text { Synovial ICIB, } \\
\text { degeneration, and } \\
\text { inflammation; } \\
\mathrm{IHC}^{+}\end{array}$ \\
\hline & $\begin{array}{l}\mathrm{TEM}^{+}, \mathrm{CD}^{\circ} 8^{+} / \\
\mathrm{EBOV}^{-} \mathrm{GP}^{+}, \mathrm{CD}^{+} 4^{+} / \\
\mathrm{EBOV}^{-} \mathrm{GP}^{+}\end{array}$ & & & & & \\
\hline NHP 6 & $\begin{array}{l}\text { Synovial ICIB, } \\
\text { degeneration, and } \\
\text { inflammation; } \\
\text { intravascular } \\
\text { thrombi, } \mathrm{IHC}^{+} \text {, } \\
\text { TEM }^{-}\end{array}$ & 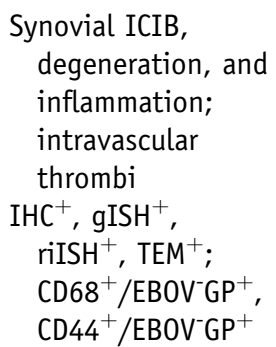 & $\mathrm{NSF} ; \mathrm{IHC}^{+}, \mathrm{gISH}^{+}$ & $\begin{array}{l}\text { NSF } \\
\mathrm{IHC}^{+}\end{array}$ & $\begin{array}{l}\text { Synovial ICIB, } \\
\text { degeneration, and } \\
\text { inflammation; } \\
\text { intravascular } \\
\text { thrombi; } \mathrm{IHC}^{+}, \\
\text {gISH }^{+}, \text {riISH }^{+}\end{array}$ & $\mathrm{NSF} ; \mathrm{IHC}^{-}$ \\
\hline NHP 8 & NSF, $\mathrm{IHC}^{-}, \mathrm{TEM}^{-}$ & $\begin{array}{l}\text { Synovial ICIB; } \mathrm{IHC}^{+}, \\
\mathrm{gISH}^{+} ; \mathrm{CD}^{+} 8^{+} / \\
\mathrm{EBOV}^{-} \mathrm{GP}^{+} \\
{\mathrm{CD} 44^{+} / \mathrm{EBOV}^{-} \mathrm{GP}^{+}}^{\mathrm{TEM}^{-}}\end{array}$ & $\mathrm{NSF} ; \mathrm{IHC}^{+}$ & $\begin{array}{l}\mathrm{NSF} \\
\mathrm{IHC}^{+}\end{array}$ & NSF; IHC ${ }^{-}$ & NSF; $\mathrm{IHC}^{-}$ \\
\hline Total & $4 / 5$ & $6 / 8$ & $5 / 5$ & $3 / 5$ & $2 / 5$ & $1 / 5$ \\
\hline
\end{tabular}

EBOV, Ebola virus; gISH, EBOV genome RNAscope in situ hybridization; GP, glycoprotein; ICIB, intracytoplasmic inclusion bodies; IHC, immunohistochemistry; NE, not examined; NHP, nonhuman primate; NSF, no significant findings; riISH, EBOV replicative intermediate RNAscope in situ hybridization; TEM, transmission electron microscopy.

on day 7 for HFLS infections. After the 30-minute fixation, the chambers were removed, and the slides were placed in $10 \%$ neutral buffered formalin and stored at $4{ }^{\circ} \mathrm{C}$ until processed. ISH was performed using the manual RNAscope 2.5 HD RED kit (catalog number 322360; Advanced Cell Diagnostics). Briefly, cultured cells adherent to chamber slides were fixed in $10 \%$ neutral buffered formalin, rinsed in phosphate-buffered saline, and washed with graded ethanol. Next, the slides were treated with hydrogen peroxide for 10 minutes at room temperature to block potential endogenous peroxidase staining. The slides were then heated in $1 \mathrm{X}$ Target Retrieval solution (catalog number 322000) in a thermoregulated decloaking chamber for 10 minutes at $95^{\circ} \mathrm{C}$, followed by enzymatic digestion by incubation in a $1: 15$ solution of Protease III (catalog number 322337) and phosphate-buffered saline for 20 minutes at $40^{\circ} \mathrm{C}$ while enclosed in a humidity-controlled hybridizer oven system. After deionized water rinses, the nucleic acid replicative intermediate target probes, antigenomic EBOV (catalog number 527491) and antigenomic MARV (catalog number 
Table 2 Timecourse of Joint Infection by Immunohistochemistry in Rhesus Macaques Acutely Infected with Ebola Virus/Kikwit

\begin{tabular}{|c|c|c|c|c|c|c|c|}
\hline \multirow[b]{2}{*}{ Animal no. } & \multirow{2}{*}{$\begin{array}{l}\text { Postinfection } \\
\text { day }\end{array}$} & \multicolumn{2}{|c|}{ Stifle } & \multicolumn{2}{|c|}{ Shoulder } & \multicolumn{2}{|l|}{ Hip } \\
\hline & & Left & Right & Left & Right & Left & Right \\
\hline NHP ${ }^{\text {Kik-nh }} 1$ & 3 & - & - & - & - & - & - \\
\hline NHP ${ }^{\text {Kik-nh }} 2$ & 3 & - & - & - & - & - & - \\
\hline NHP ${ }^{\text {Kik-nh }} 3$ & 3 & - & - & - & - & - & - \\
\hline NHP ${ }^{\text {Kik-nh }} 4$ & 4 & - & - & - & - & - & - \\
\hline NHP Kik-nh 5 & 4 & - & - & - & - & - & - \\
\hline NHP Kik-nh 6 & 4 & - & - & - & - & - & - \\
\hline NHP ${ }^{\text {Kik-nh }} 7$ & 5 & - & - & - & - & - & - \\
\hline NHP Kik-nh 8 & 5 & - & - & - & - & - & - \\
\hline NHP Kik-nh 9 & 5 & - & - & - & - & - & - \\
\hline NHP ${ }^{\text {Kik-nh }} 10$ & 6 & - & + & + & - & - & - \\
\hline NHP ${ }^{\text {Kik-nh }} 11$ & 6 & - & - & - & - & - & - \\
\hline NHP ${ }^{\text {Kik-nh }} 12$ & 6 & - & - & - & - & - & - \\
\hline NHP ${ }^{\text {Kik-nh }} 13$ & $6 *$ & - & + & - & - & - & - \\
\hline NHP ${ }^{\text {Kik-nh }} 14$ & $6 *$ & + & + & - & - & - & - \\
\hline NHP ${ }^{\text {Kik-nh }} 15$ & $7 *$ & + & + & + & + & + & + \\
\hline NHP ${ }^{\text {Kik-nh }} 16$ & $7^{*}$ & - & - & - & - & + & + \\
\hline NHP ${ }^{\text {Kik-nh }} 17$ & $8^{*}$ & + & + & + & + & + & + \\
\hline NHP ${ }^{\text {Kik-nh }} 18$ & $8^{*}$ & + & + & + & + & + & - \\
\hline
\end{tabular}

*These animals reached end point criteria and were euthanatized. NHP $\mathrm{P}^{\mathrm{Kik}-\mathrm{nh}}$, nonhuman primate with Kikwit natural history.

527301), were applied to the slides and incubated for 2 hours. After hybridization and rinsing the slides in $1 \mathrm{X}$ wash buffer solution, the resulting signal was amplified then detected by incubating the slides in a red substrate-chromogen solution for 10 minutes at room temperature, followed by hematoxylin counterstain (catalog number 7211; Thermo Fisher).

For plaque assay, virus was serially diluted 1:10 for a total of 7 dilutions in Dulbecco's modified Eagle's medium with with $5 \%$ heat-inactivated fetal bovine serum. After removal of media from the 6-well plates, $300 \mu \mathrm{L}$ of the appropriate dilutions were added to a $95 \%$ confluent monolayer of Vero cells (ATCC, Manassas, VA) for maEBOV/Yam or to a $90 \%$ confluent monolayer of Vero E6 cells (BEI Resources) for EBOV/Mak, EBOV/Kik, and
MARV/Ang. Plates were incubated at $37^{\circ} \mathrm{C}$ in $5 \%$ carbon dioxide for 1 hour with rocking every $10 \pm 5$ minutes. After incubation, a 1:1 ratio of $2.5 \%$ Avicel (FMC Biopolymer, Philadelphia, PA) and $2 \times$ Dulbecco's modified Eagle's medium with with $10 \%$ heat-inactivated fetal bovine serum, antibiotic-antimycotic, and glutaMAX was added to each well and incubated at $37^{\circ} \mathrm{C}$ for 6 days for MARV/Ang, 7 days for EBOV/Mak, or 8 days for EBOV/Kik and maEBOV/Yam. Plates were fixed and stained using $0.2 \%$ crystal violet stain (Ricca Chemical, Pocomoke City, MD) in 10\% neutral-buffered formalin (Thermo Fisher) and plaques were manually counted.

\section{Results}

\section{IHC Shows Frequent Filovirus Infection of the Synovium}

Six EBOV/Kik-infected macaques died or were euthanatized on postinoculation day (PID) $5(n=1), 6(n=1), 7$ $(n=2)$, or $8(n=2)$. Because study macaques were confined within cages and often moved little after the onset of FVD, it was not possible to rigorously assess for clinical signs of arthralgia (eg, gait analysis). Stifles were grossly normal, and samples from both stifles were collected. Histologic analysis findings were unremarkable except for minimal focal acute hemorrhage and inflammation in a single stifle. In all six macaques, there was positive immunostaining of the stifle synovial intima for EBOV glycoprotein (Figure 1A) and matrix protein (VP40) (Figure 1B); staining was bilateral in four animals and unilateral in two (Supplemental Table S1). Immunostaining was variable and ranged from single small foci of positivity (Supplemental Figure S1) to nearly diffuse positivity across the synovial intima. EBOV/Mak-infected macaques succumbed to disease or were euthanatized on PID $7(n=4)$ or $8(n=1)$; samples from both stifles were collected from each animal. There were no gross abnormalities, and only a single macaque had histologic abnormalities that consisted of bilateral
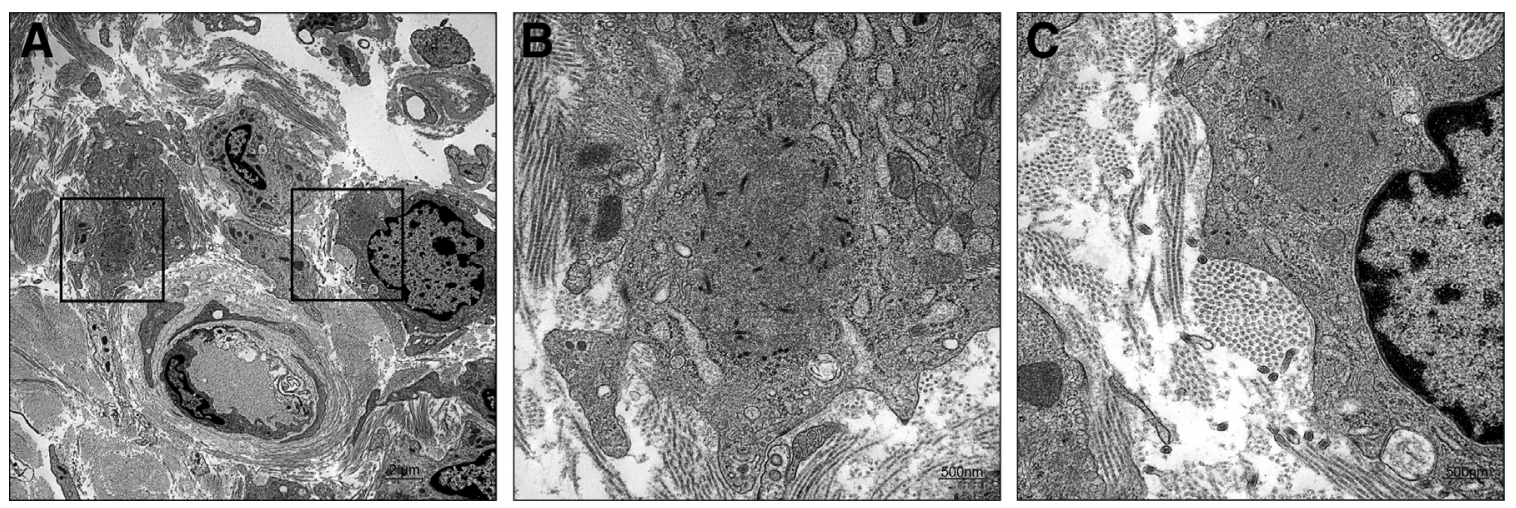

Figure 3 Transmission electron micrograph of the left stifle of nonhuman primate 5 showing Ebola virus (EBOV) infection of the synovium. Viral inclusions with nucleocapsids are present within two intimal type A synoviocytes (macrophages). Boxed areas in A are shown at higher magnification in B and C. Mature EBOV virions are present extracellularly in the interstitium (C). Joint space is oriented at top right. Scale bars: $2 \mu \mathrm{m}(\mathbf{A}) ; 500 \mathrm{~nm}(\mathbf{B}$ and C). 

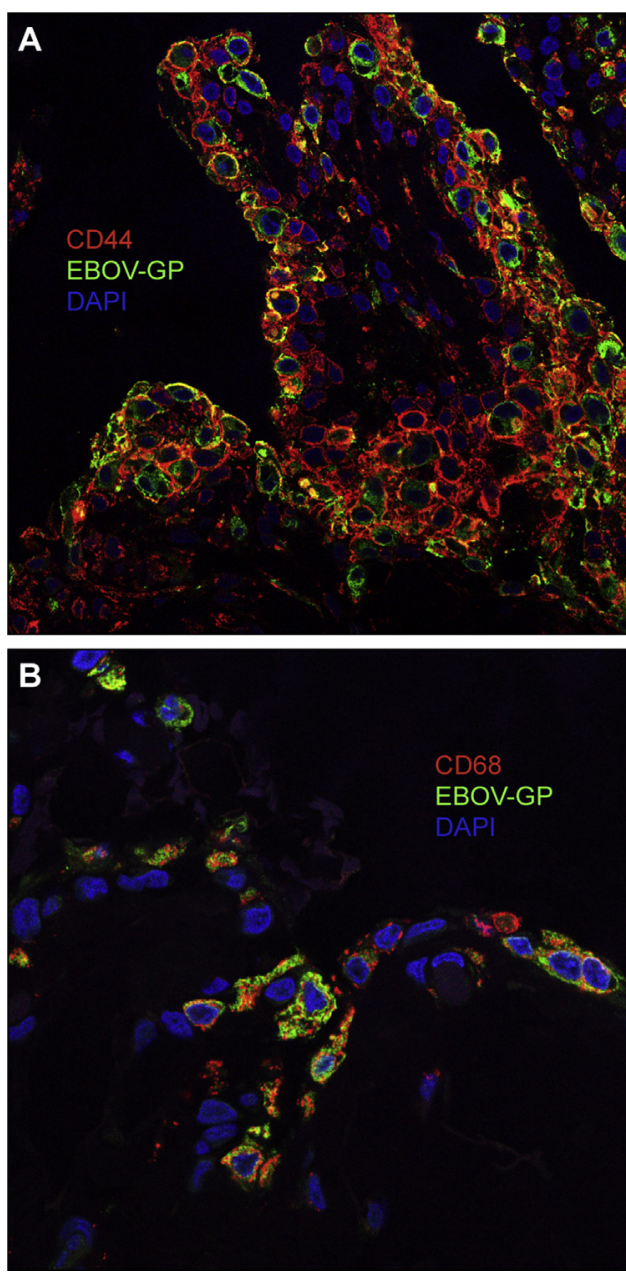

Figure 4 Immunofluorescence shows filovirus targeting of type $A$ and $B$ synoviocytes in vivo. Confocal imaging shows colocalization of Ebola virus (EBOV) glycoprotein (Alexa Fluor 488, green) in $\mathrm{CD}_{4} 4^{+}$(Alexa Fluor 594, red) type B synoviocytes (A) as well as $\mathrm{CD}^{+} 8^{+}$(Alexa Fluor 594, red) type A synoviocytes (B) in mouse-adapted EBOV/Yambuku-Mayinga-infected rhesus stifle. Joint space is at the top. Original magnification, $\times 400$ (A and B).

minimal synoviocyte degeneration and necrosis with rare inclusions. Positive immunostaining was present bilaterally in three of five rhesus macques infected with EBOV/Mak and was unilateral in a fourth. In all four animals, positive staining was only present in scattered clusters of cells. A single animal was negative bilaterally. MARV/Ang-infected rhesus macaques died or were euthanatized on PID $6(n=$ $2), 7(n=1)$, or $8(n=2)$; only samples of the right stifle were collected. There were no gross or histologic findings. Four of five animals had positive MARV immunostaining results of the stifle synovium, ranging from diffuse $(n=1)$ (Figure 1, C and D) to focally extensive $(n=1)$ to scattered foci of few positive cells $(n=2)$ (Supplemental Figure S2).

Eight of 12 rhesus macaques experimentally inoculated in two cohorts with ma-EBOV/Yam died or reached end point criteria and were euthanatized during acute infection ( $n=3 / 6$ and $n=5 / 6$ ) on PIDs 9 and 10. Joints were not grossly swollen or erythematous. In the first cohort, samples of synovium, joint capsule, and meniscus were collected for histologic analysis from the right stifle only. In the second cohort, synovial membrane samples for histologic analysis were collected from stifles, hips, and shoulders bilaterally. By routine histologic analysis, rare to occasional eosinophilic to amphophilic intracytoplasmic viral inclusions were visible in intimal synovial cells in four stifle joints and a single hip joint from five different animals (Figure 2A and Table 1). In six stifles from four animals (bilateral in two), there was also infiltration of low numbers of macrophages and neutrophils (inflammation) (Figure 2B), with intravascular thrombi in a single macaque in which there was also widespread systemic and pulmonary thrombosis (disseminated intravascular coagulation). Similar mild inflammation was present in three shoulder joints in two animals and three coxofemoral joints in three animals. Inflammation was present within multiple joints in 3 of 5 animals, including stifle, hip, and both shoulders in a single animal (NHP5). Gross and histologic examination findings of stifles, hips, and shoulders from the four survivors of ma-EBOV/Yam infection at PID 185-364 were unremarkable.

Immunostaining results of intimal synovial cells from maEBOV/Yam-infected rhesus for EBOV GP and VP40 antigens was variable and ranged from single small foci of positivity to nearly diffuse positivity across the membrane (Figure 2, C-F). Ten of 13 stifles evaluated had positive immunostaining results of the synovial intima, affecting all eight ma-EBOV/Yam-infected animals that died of acute disease. Eight of 10 shoulder joints evaluated had positive immunostaining of the intima, which was unilateral in two animals and bilateral in three. Only three hip joints from three different subjects were immunoreactive for EBOV. Positive immunostaining results were always present in joints with histologically identifiable inflammation and degeneration and were nearly always present in joints with histologically identifiable viral inclusion bodies. Viral antigen was variably present in histologically normal joints. There was no consistent association between histologic abnormalities in the synovium and the extent and distribution of positive immunostaining results, with diffuse positive staining results in some histologically normal synovium. No correlation was found between the presence or extent of positive immunostaining results and time to death for any of the viruses.

An additional 18 rhesus macques infected with EBOV/ Kik were enrolled in a natural history time course study. Three animals were euthanatized per timepoint on PIDs 3, 4, 5, and 6; an additional six animals reached end point criteria because of clinical EVD and were euthanatized on days 6 $(n=2), 7(n=2)$, and $8(n=2)$. All joints were grossly and histologically normal. None of the animals euthanatized on PID 3, 4, or 5 had detectable virus by IHC in any joint. A single animal electively euthanatized on PID 6 had positive intimal staining results in the right stifle and left shoulder (Table 2). The two animals that reached end point criteria and were euthanatized on PID 6 had positive results for one or both stifles. All animals that reached end point criteria on PIDs 7 and 8 had multiple positive joints. No correlation 
Table 3 RT-PCR Results from Rhesus Macaques Acutely Infected with Mouse-Adapted EBOV/Yambuku-Mayinga

\begin{tabular}{|c|c|c|c|c|c|}
\hline Animal no. & $\begin{array}{l}\text { Necropsy } \\
\text { day }\end{array}$ & $\begin{array}{l}\text { Plasma genome } \\
\text { equivalents per mL } \\
\text { (EBOV glycoprotein) }\end{array}$ & $\begin{array}{l}\text { Collection } \\
\text { location }\end{array}$ & $\begin{array}{l}\text { Genome equivalents } \\
\text { per } \mathrm{mL} \text { (EBOV } \\
\text { glycoprotein) }\end{array}$ & $\begin{array}{l}\text { Genome equivalents } \\
\text { per } \mathrm{mL} \text { (EBOV } \\
\text { nucleoprotein) }\end{array}$ \\
\hline NHP2 & 10 & $8.20 \times 10^{5}$ & Right stifle & $3.31 \times 10^{8}$ & $1.80 \times 10^{9}$ \\
\hline NHP3 & 10 & $1.53 \times 10^{7}$ & Right stifle & $1.87 \times 10^{7}$ & $5.49 \times 10^{7}$ \\
\hline NHP4 & 09 & $3.92 \times 10^{9}$ & Right stifle & $2.91 \times 10^{7}$ & $8.33 \times 10^{6}$ \\
\hline \multirow[t]{2}{*}{ NHP6 } & 10 & $9.45 \times 10^{7}$ & Left stifle & $5.40 \times 10^{7}$ & $8.41 \times 10^{6}$ \\
\hline & & & Right stifle & $3.20 \times 10^{7}$ & $5.63 \times 10^{6}$ \\
\hline \multirow[t]{2}{*}{ NHP7 } & 9 & $5.09 \times 10^{8}$ & Left stifle & $2.15 \times 10^{8}$ & $9.42 \times 10^{7}$ \\
\hline & & & Right stifle & $3.85 \times 10^{6}$ & $8.64 \times 10^{5}$ \\
\hline NHP8 & 9 & $2.49 \times 10^{8}$ & Left stifle & $1.59 \times 10^{4}$ & $2.66 \times 10^{3}$ \\
\hline
\end{tabular}

EBOV, Ebola virus; NHP, nonhuman primate.

was found between peripheral blood viremia and the presence or extent of joint infection in these animals.

\section{ISH Confirms IHC Findings}

A subset of IHC-positive joints (7 stifles, 3 shoulders, and 1 hip) from ma-EBOV/Yam-infected macaques were stained for viral genome by RNAscope. All tested positive with an ISH staining pattern of the synovial intima similar to the respective IHC pattern (Figure 2G). A subset of these, including 5 stifles, 2 shoulders, and 1 hip, was also stained using probes for replicative intermediate (antigenome) RNA, and all tested positive, indicating active viral replication within the synovial intima (Figure 2H). ISH using probes against EBOV genome tested negative in three stifles examined from two ma-EBOV/Yam-infected macaques that survived after severe clinical EVD. Stifle joints from an uninfected Chinese rhesus macaque tested negative for EBOV and MARV viral proteins and RNA (Supplemental Figure S3).

\section{TEM Shows Virus in Synovium}

Samples of stifle synovium for TEM were collected from four euthanatized animals in the second ma-EBOV/Yam cohort only. Mature virus particles, inclusions that contained nucleocapsids, and budding viral particles were observed within and adjacent to synovial intimal and subintimal macrophages from two animals (Figure 3). Virus was not observed in samples from the other two animals (half of which were also IHC negative).

\section{Filoviruses Infect Type A and Type B Synoviocytes}

Stifles from four ma-EBOV/Yam-infected rhesus were stained by immunofluorescence to identify infected synovial cell types. In all four animals, intimal synovial cells immunolabeling for EBOV glycoprotein included both
CD44 ${ }^{+}$type B (fibroblast-like) (Figure $4 \mathrm{~A}$ ) and CD68 ${ }^{+}$type A (macrophage-like) (Figure 4B) synoviocytes.

\section{EBOV Genomes Are Frequently Present in Synovial Fluid}

Using primer sets that detect both glycoprotein and nucleoprotein, viral RNA was detected in all swabs of synovial fluid from stifle joints of ma-EBOV/Yam macaques that died of acute disease $(n=12)$ (Table 3$)$. Although care was taken during collection, contamination of swabs by peripheral blood cannot be excluded for all samples. Because synovial fluid was collected via dry swab and placed into 1 $\mathrm{mL}$ of media (resulting in a large unquantified dilution factor), a true viral titer per milliliter of synovial fluid cannot be calculated. Even without correcting for the dilution, 4 of 12 synovial fluid swab titers are within one $\log$ of the genome equivalents per milliliter when compared with the corresponding plasma samples, suggesting accumulation of virus in this fluid rather than just a small contribution from blood contamination. Bilateral stifle synovial fluid swabs from all four ma-EBOV/Yam survivors had negative quantitative RT-PCR results.

\section{Human Synoviocytes Are Permissive to Filovirus Infection in Vitro}

Cultured primary HFLS cells were permissive to EBOV/Kik and MARV/Ang infection in vitro as demonstrated by viral replication (including intracellular nucleocapsids, budding, and extracellular mature viral particles) observed by ultrastructural examination (Figure 5). In addition, HFLS cells stained positively by RNAscope ISH using probes against replicative intermediate (antigenome) targets after in vitro infection with EBOV/Mak, ma-EBOV/Yam, EBOV/Kik, or MARV/Ang (Figure 6, A-E), consistent with active virus replication. Mock-infected cells tested negative for viral probe hybridization (Figure 6F). Interestingly, infected 

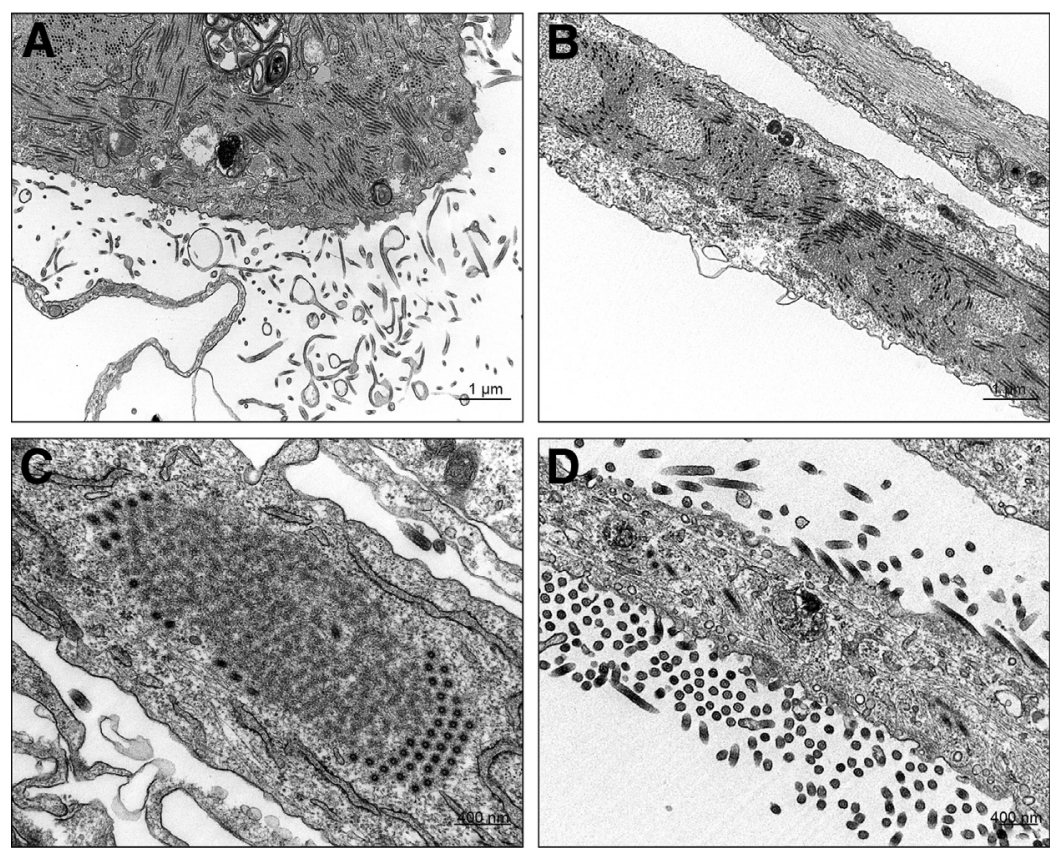

Figure 5 Transmission electron micrographs showing Ebola and Marburg virus infection of human fibroblast-like synoviocytes. A: Ebola viral inclusions with nucleocapsids, budding particles, and extracellular mature virions are present within and surrounding an infected spindled cell. B: Ebola viral inclusions and nucleocapsids. C: Marburg viral inclusion with nucleocapsids. D: Budding and extracellular mature Marburg virus particles attached to and surrounding an infected cell. Scale bars: $1 \mu \mathrm{m}$ (A and $\mathbf{B})$; $400 \mathrm{~nm}$ (C and D).
HFLS cells had no significant cytopathic effect after 8 days of incubation, in contrast to infected Huh-7 cells (Supplemental Figure S4). Daily supernatant samples from HFLS and Huh7 cells infected with EBOV/Mak, ma$\mathrm{EBOV} / \mathrm{Yam}, \mathrm{EBOV} / \mathrm{Kik}$, or MARV/Ang were titered by plaque assay using an avicel overlay. All viruses grew well in the control cell line, Huh7, reaching peak titer typically at approximately day 4 or 5 . HFLS cells were permissive to infection by all four filoviruses tested, with MARV/Angola exhibiting the most viral growth at $2.73 \times 10^{4} \mathrm{PFU} / \mathrm{mL}$, followed by EBOV/Mak at $1.0 \times 10^{4} \mathrm{PFU} / \mathrm{mL}$, ma-EBOV/ Yam at $2.1 \times 10^{3} \mathrm{PFU} / \mathrm{mL}$, and EBOV/Kik, reaching a titer no higher than $3.0 \times 10^{2} \mathrm{PFU} / \mathrm{mL}$. Although viral titers in infected Huh7 cell supernatants had plateaued or started to decrease by day 7, all infections in HFLS cells appeared to still be increasing in titer at the end of the growth curve on day 7 (Supplemental Figure S5).

\section{Discussion}

The finding of frequent and often widespread infection of the synovial intima by EBOV and MARV is novel and could potentially contribute to the high incidence of joint pain during acute FVD. ${ }^{2-5,17}$ Filovirus persistence in immune privileged sites, including testes, brain, and eye, in survivors of acute FVD may cause recrudescence of clinical disease and further spread of infection to new hosts. ${ }^{14,15,39-43}$ Within synovial joints, the articular cartilage is considered an immune privileged site, ${ }^{19,20}$ and pathogen persistence in joints has been demonstrated for other viruses as well as for bacteria. ${ }^{44-47}$ During acute filoviral infection, the finding of productive infection of the synovial intima with viral genomes present in the synovial fluid bathing the articular cartilage satisfies the necessary conditions for potential filovirus infection of this avascular immune privileged site. Although there was no positive quantitative RT-PCR or ISH signal in the stifles of four maEBOV/Yam-infected survivors at PID 185 or 364, the possibility of viral persistence in the synovial joints (including articular cartilage) at earlier convalescent timepoints will be addressed in future studies. Despite the widespread filovirus infection of the synovium as demonstrated by IHC and ISH, there was little tissue or leukocytic response and no fibrin exudation present in any of the animals. Although widespread necrosis with minimal inflammation is a typical feature of acute FVD in many organs (classically the liver) in humans and NHP models, widespread infection without evident gross or histologic lesions has been reported in certain tissues (eg, reproductive tract). ${ }^{29,36}$ The in vivo findings of widespread infection with minimal cell death in the synoviocytes are also consistent with the lack of viral cytopathic effect in synoviocytes in vitro. In addition, there was variability in the extent of synoviocyte infection in different animals and by different filoviruses, both in vitro and in vivo, for reasons that are not currently understood. However, the repeatability of the synovial infections across different hosts and viruses is a testament to the robustness of the results.

The underlying pathophysiologic mechanisms of arthralgia in patients with acute or convalescent FVD are not known. ${ }^{13}$ Potential mechanisms of viral arthritis or arthralgia include direct viral infection of synovial cells with loss of nonadherence properties, leading to adhesions, or release of cytokines and metalloproteinases with possible altered synovial fluid composition, leading to a loss of lubricity and/or 

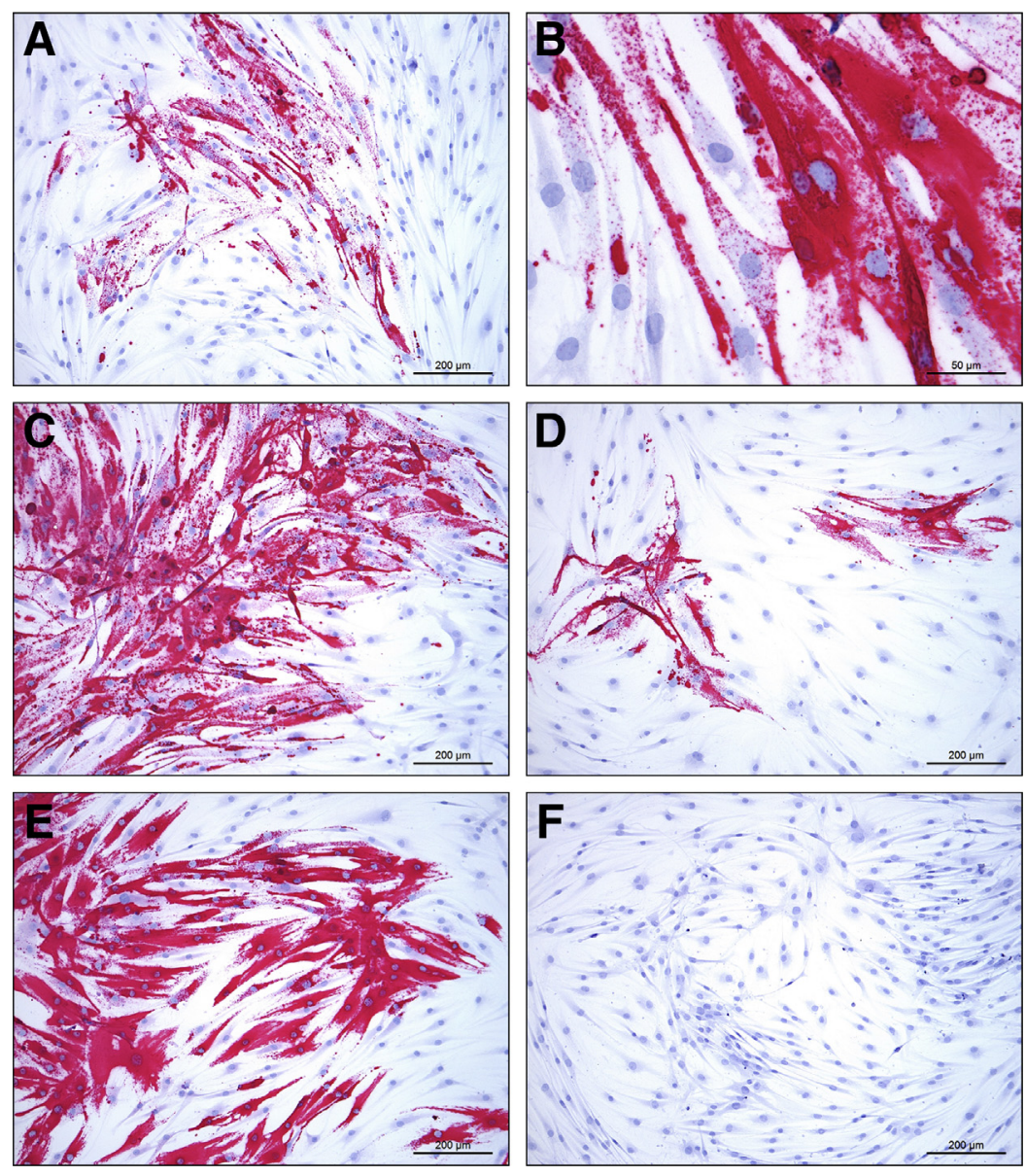

Figure 6 Cultured primary human fibroblast-like synoviocytes were infected with Ebola virus (EBOV) or Marburg virus (MARV), fixed, and stained by in situ hybridization using probes against the respective viral replicative intermediate (antigenome) RNA. All viruses were infected at the same multiplicity of infection, with minimal cytopathic effect. A-E: Human fibroblast-like synoviocytes (HFLS) infected with EBOV/Makona-C05 (A and B), mouse-adapted EBOV/ Yambuku-Mayinga (C), EBOV/Kikwit (D), or MARV/Angola (E). F: Mock-infected HFLS cells probed for EBOV antigenome have no positive staining results. Red substrate chromogen with hematoxylin counterstain. Scale bars: $200 \mu \mathrm{m}$ (A and C-F); $50 \mu \mathrm{m}$ (B). metabolic damage to avascular chondrocytes, generation of antigen-antibody complexes, or the development of autoantibodies by molecular mimicry and cryptic antigens. ${ }^{48-50}$ One report described significantly higher serum IgG titers in EVD survivors with arthralgia than those without, suggesting a role for antibodies (eg, type II hypersensitivity) in the pathogenesis of joint symptoms. ${ }^{11}$ More recently, no association between antibody titers and joint pain was found in a large cohort of Liberian EVD survivors. ${ }^{12}$ The occurrence of effusive polyarthritis in two patients coincident with delayed active central nervous system viral infection (an immune privileged site) suggests a possible autoimmune or immune-mediated process related to viral recrudescence. ${ }^{14,15}$ Autoantibodies (including anti-double-stranded DNA) have been elicited in mouse and NHP experimental models and identified in a small sample of EVD survivors. ${ }^{51}$ The same study found accumulation of antibodies in the joints of EVD survivor mice compared with uninfected controls but did not report any radiographic or histologic assessment of the joints. However, a rheumatologic assessment of arthralgias in one study of human EVD survivors has not been thought to be consistent with an autoimmune process, although no serology was reported. ${ }^{7}$ Furthermore, a longitudinal study of Liberian EVD survivors found no association between joint pain (or any other sequela) and markers of inflammation or immune activation. ${ }^{52}$
Infection of type B (fibroblast-like) synoviocytes, which have an important immunomodulatory role in the pathogenesis of rheumatoid arthritis, ${ }^{26}$ could have significant deleterious downstream effects. Expansion of the subintimal interstitium as a sequela to acute inflammation (scarring) with reduced capillary density may impair the ability of synovial fluid to metabolically support articular cartilage. ${ }^{48}$ However, consistent with the symptoms and physical examination findings of human survivors, no histologic evidence of arthritis was present in the synovium of four ma-EBOV/Yam-infected survivor animals in the present study. Only two of the four developed severe clinical EVD, with mild clinical signs in the other two, and the animals were euthanatized at 6 or 12 months after infection (R.S.B., unpublished data). Interestingly, arthritis or arthralgia has been reported as a common adverse effect with EBOV vaccines that express the EBOV glycoprotein in a replication competent rhabdovirus vector, although the mechanism(s) remain unexplored. ${ }^{53-55}$ Both arthralgias (17.1\% incidence) and arthritis (5.1\% incidence) have been reported in humans up to 25 days after receiving the rVSV $\Delta \mathrm{G}$ ZEBOV glycoprotein vaccine, with rVSV RNA identified within the synovial fluid, implicating viral replication in the pathogenesis. ${ }^{56}$ Vaccine-associated arthritis as an adverse effect has been correlated with higher anti-EBOV glycoprotein IgG titers in a small number of patients ${ }^{57}$; however, more 
recent close follow-up of a group of reactively vaccinated close contacts found an association of arthralgia with T-cell immune responses $\left(\mathrm{CD}^{+}{ }^{+}\right.$interferon- $\gamma$ and $\mathrm{CD} 4^{+} \mathrm{IL}-2$ secreting cells) but not $\operatorname{IgM}, \mathrm{IgG}$, or neutralizing antibodies. ${ }^{58}$

This study provides preliminary data on the frequent infection of synovial intimal cells of both macrophage and fibroblast lineage during acute FVD in NHPs; notably, synovial tissues of 28 of 30 NHPs (93\%; 64 of 96 joints examined) with terminal FVD were infected. Primary human fibroblasts are also permissive to filovirus infection in vitro with the same virus stocks used to infect NHPs in vivo, resulting in amplification of infectious virus. Although viral infection was apparent through plaque assay, infection of the human synoviocyte cells did not result in visible morphologic changes during the growth curve. Future work will focus on the duration of infection and whether a persistent infection can be established in this cell type. The infection of human synoviocytes thus may be at least one potential source of the arthralgia that has been commonly reported in EVD survivors.

When the time course of infection with EBOV/Kik was evaluated, joints became involved relatively late in the disease course, beginning only on PID 6 . This finding has significance for treated human patients because controlling virus replication early after exposure may reduce the chance of infection in these immune privileged sites. Further development of the NHP filovirus infection models described here provide an opportunity to study viral dynamics and host responses in these tissues in the presence or absence of antifilovirus therapeutics. In addition, an in vitro method is described here for studying filovirus replication in primary human cells, which may provide insights into mechanisms of persistent infection as well as studying medical countermeasures to clear infection in these cells.

Limitations of this study include lack of functional or imaging evaluation of joints during acute disease, direct evaluation of articular hyaline cartilage, or evaluation of synovial fluid quality and for the presence of inflammatory mediators or cytokines. Future experiments will focus on bridging the gap left by these limitations. Mechanistic studies of survivors of experimental (and natural) FVD, including imaging and pathology, are greatly needed for rheumatologic and other disease sequelae. Given the widespread synovial infection described herein with acute FVD, convalescent inflammation as a consequence of viral control in survivors that results in long term joint damage and scarring is possible. Additional studies on the distribution, kinetics, and clearance of joint infection in acute illness and convalescence would lend insight into pathogenesis in human FVD survivors as well as identify timeframes for preventive interventions.

\section{Acknowledgments}

We thank Nejra Isic and Maureen Abbott for histology support, Lisa Mistretta for animal care, Jiro Wada for figure preparation, Laura Bollinger for critically reviewing and editing the manuscript, Nichole Deiuliis for assistance with cell culture, Joseph Cornish for assisting in the development of confocal techniques, and Dr. Anthony Griffiths (Texas Biomedical Research Institute) for mouse-adapted Ebola virus.

\section{Author Contributions}

T.K.C., R.S.B., L.E.H., P.B.J., and I.C. conceptualized the study; T.K.C., R.S.B., J.L., J.G.B., A.M.W.H., R.J.H., D.X.L., D.L.P., D.M.G., O.R., J.K.B., K.R.H., and R.F.J. designed the methodology; T.K.C., R.S.B., D.X.L., D.L.P., and J.L. analyzed the results; T.K.C., R.S.B., D.M.G., and J.L. wrote the original draft; all authors reviewed and edited the draft; L.E.H. and P.B.J. supervised the study; R.S.B. and J.L. were responsible for project administration; L.E.H. acquired funds. T.K.C. is the guarantor of this work and, as such, had full access to all the data in the study and takes responsibility for the integrity of the data and the accuracy of the data analysis.

\section{Supplemental Data}

Supplemental material for this article can be found at http://doi.org/10.1016/j.ajpath.2020.05.013.

\section{References}

1. Kuhn JH, Adachi T, Adhikari NKJ, Arribas JR, Bah IE, Bausch DG, et al: New filovirus disease classification and nomenclature. Nat Rev Microbiol 2019, 17:261-263

2. Prati C, Chirouze C, Wendling D: Can we run into Ebola in rheumatology departments? Joint Bone Spine 2015, 82:394-396

3. MacNeil A, Farnon EC, Wamala J, Okware S, Cannon DL, Reed Z, Towner JS, Tappero JW, Lutwama J, Downing R, Nichol ST, Ksiazek TG, Rollin PE: Proportion of deaths and clinical features in Bundibugyo Ebola virus infection, Uganda. Emerg Infect Dis 2010, 16:1969-1972

4. Dietz PM, Jambai A, Paweska JT, Yoti Z, Ksiazek TG: Epidemiology and risk factors for Ebola virus disease in Sierra Leone-23 May 2014 to 31 January 2015. Clin Infect Dis 2015, 61:1648-1654

5. Bwaka MA, Bonnet MJ, Calain P, Colebunders R, De Roo A, Guimard Y, Katwiki KR, Kibadi K, Kipasa MA, Kuvula KJ, Mapanda BB, Massamba M, Mupapa KD, Muyembe-Tamfum JJ, Ndaberey E, Peters CJ, Rollin PE, Van den Enden E, Van den Enden E: Ebola hemorrhagic fever in Kikwit, Democratic Republic of the Congo: clinical observations in 103 patients. J Infect Dis 1999 , 179(Suppl 1):S1-S7

6. Qureshi AI, Chughtai M, Loua TO, Pe Kolie J, Camara HF, Ishfaq MF, N'Dour CT, Beavogui K: Study of Ebola virus disease survivors in Guinea. Clin Infect Dis 2015, 61:1035-1042

7. Pers YM, Sow MS, Taverne B, March L, Izard S, Etard JF, Barry M Toure A, Delaporte E: Characteristics of the musculoskeletal symptoms observed among survivors of Ebola virus disease in the Postebogui cohort in Guinea. Rheumatology (Oxford) 2017, 56: 2068-2072

8. Tiffany A, Vetter P, Mattia J, Dayer JA, Bartsch M, Kasztura M, Sterk E, Tijerino AM, Kaiser L, Ciglenecki I: Ebola virus disease complications as experienced by survivors in Sierra Leone. Clin Infect Dis 2016, 62:1360-1366 
9. Mattia JG, Vandy MJ, Chang JC, Platt DE, Dierberg K, Bausch DG, Brooks T, Conteh S, Crozier I, Fowler RA, Kamara AP, Kang C, Mahadevan S, Mansaray Y, Marcell L, McKay G, O’Dempsey T, Parris V, Pinto R, Rangel A, Salam AP, Shantha J, Wolfman V, Yeh S, Chan AK, Mishra S: Early clinical sequelae of Ebola virus disease in Sierra Leone: a cross-sectional study. Lancet Infect Dis 2016, 16:331-338

10. Nanyonga M, Saidu J, Ramsay A, Shindo N, Bausch DG: Sequelae of Ebola virus disease, Kenema District, Sierra Leone. Clin Infect Dis 2016, 62:125-126

11. Rowe AK, Bertolli J, Khan AS, Mukunu R, Muyembe-Tamfum JJ, Bressler D, Williams AJ, Peters CJ, Rodriguez L, Feldmann H, Nichol ST, Rollin PE, Ksiazek TG: Clinical, virologic, and immunologic follow-up of convalescent Ebola hemorrhagic fever patients and their household contacts, Kikwit, Democratic Republic of the Congo. Commission de Lutte contre les Epidemies a Kikwit. J Infect Dis 1999, 179(Suppl 1):S28-S35

12. Group PIS, Sneller MC, Reilly C, Badio M, Bishop RJ, Eghrari AO, Moses SJ, Johnson KL, Gayedyu-Dennis D, Hensley LE, Higgs ES, Nath A, Tuznik K, Varughese J, Jensen KS, Dighero-Kemp B, Neaton JD, Lane HC, Fallah MP: A longitudinal study of Ebola sequelae in Liberia. N Engl J Med 2019, 380:924-934

13. Amissah-Arthur MB, Poller B, Tunbridge A, Adebajo A: Musculoskeletal manifestations of Ebola virus. Rheumatology (Oxford) 2018, 57:28-31

14. Jacobs M, Rodger A, Bell DJ, Bhagani S, Cropley I, Filipe A, et al: Late Ebola virus relapse causing meningoencephalitis: a case report. Lancet 2016, 388:498-503

15. Howlett P, Brown C, Helderman T, Brooks T, Lisk D, Deen G, Solbrig M, Lado M: Ebola virus disease complicated by late-onset encephalitis and polyarthritis, Sierra Leone. Emerg Infect Dis 2016, 22:150-152

16. Clark DV, Kibuuka H, Millard M, Wakabi S, Lukwago L, Taylor A, Eller MA, Eller LA, Michael NL, Honko AN, Olinger GG Jr, Schoepp RJ, Hepburn MJ, Hensley LE, Robb ML: Long-term sequelae after Ebola virus disease in Bundibugyo, Uganda: a retrospective cohort study. Lancet Infect Dis 2015, 15: 905-912

17. Knust B, Schafer IJ, Wamala J, Nyakarahuka L, Okot C, Shoemaker T, Dodd K, Gibbons A, Balinandi S, Tumusiime A, Campbell S, Newman E, Lasry E, DeClerck H, Boum Y, Makumbi I, Bosa HK, Mbonye A, Aceng JR, Nichol ST, Stroher U, Rollin PE: Multidistrict outbreak of Marburg virus disease-Uganda, 2012. J Infect Dis 2015, 212(Suppl 2):S119-S128

18. Miraglia CM: Marburgviruses: an update. Lab Med 2019, 50:16-28

19. Ochi M, Ishida O, Daisaku H, Ikuta Y, Akiyama M: Immune response to fresh meniscal allografts in mice. J Surg Res 1995, 58: 478-484

20. Theodoulou MH, Bohman L: Allograft cartilage replacements. Clin Podiatr Med Surg 2018, 35:281-293

21. Vetter P, Fischer WA 2nd, Schibler M, Jacobs M, Bausch DG, Kaiser L: Ebola virus shedding and transmission: review of current evidence. J Infect Dis 2016, 214:S177-S184

22. Harvanova D, Tothova T, Sarissky M, Amrichova J, Rosocha J: Isolation and characterization of synovial mesenchymal stem cells. Folia Biol (Praha) 2011, 57:119-124

23. Smith MD: The normal synovium. Open Rheumatol J 2011, 5: 100-106

24. Iwanaga T, Shikichi M, Kitamura H, Yanase H, Nozawa-Inoue K: Morphology and functional roles of synoviocytes in the joint. Arch Histol Cytol 2000, 63:17-31

25. Bartok B, Firestein GS: Fibroblast-like synoviocytes: key effector cells in rheumatoid arthritis. Immunol Rev 2010, 233:233-255

26. Leech MT, Morand EF: Fibroblasts and synovial immunity. Curr Opin Pharmacol 2013, 13:565-569

27. Morito T, Muneta T, Hara K, Ju YJ, Mochizuki T, Makino H, Umezawa A, Sekiya I: Synovial fluid-derived mesenchymal stem cells increase after intra-articular ligament injury in humans. Rheumatology (Oxford) 2008, 47:1137-1143

28. Steele K, Crise B, Kuehne A, Kell W: Ebola virus glycoprotein demonstrates differential cellular localization in infected cell types of nonhuman primates and guinea pigs. Arch Pathol Lab Med 2001, 125:625-630

29. Martines RB, Ng DL, Greer PW, Rollin PE, Zaki SR: Tissue and cellular tropism, pathology and pathogenesis of Ebola and Marburg viruses. J Pathol 2015, 235:153-174

30. Davis KJ, Anderson AO, Geisbert TW, Steele KE, Geisbert JB, Vogel P, Connolly BM, Huggins JW, Jahrling PB, Jaax NK: Pathology of experimental Ebola virus infection in African green monkeys. Involvement of fibroblastic reticular cells. Arch Pathol Lab Med 1997, 121:805-819

31. Cooper TK, Sword J, Johnson JC, Bonilla A, Hart R, Liu DX, Bernbaum JG, Cooper K, Jahrling PB, Hensley LE: New insights into Marburg virus disease pathogenesis in the rhesus macaque model. $\mathrm{J}$ Infect Dis 2018, 218:S423-S433

32. Bray M, Hatfill S, Hensley L, Huggins JW: Haematological, biochemical and coagulation changes in mice, guinea-pigs and monkeys infected with a mouse-adapted variant of Ebola Zaire virus. J Comp Pathol 2001, 125:243-253

33. US Department of Health and Human Services, NIH, Office of Laboratory Animal Welfare: Public Health Service Policy on Humane Care and Use of Animals. Bethesda, MD, NIH, 2015

34. Committee for the Update of the Guide for the Care and Use of Laboratory Animals; National Research Council: Guide for the Care and Use of Laboratory Animals: Eighth Edition. Washington, DC, National Academies Press, 2011

35. National Research Council Committee for the Update of the Guide for the Care and Use of Laboratory Animal: US Government Principles for Utilization and Care of Vertebrate Animals Used in Testing, Research, and Training. Washington, DC, National Academies Press, 2011

36. Perry DL, Huzella LM, Bernbaum JG, Holbrook MR, Jahrling PB, Hagen KR, Schnell MJ, Johnson RF: Ebola virus localization in the macaque reproductive tract during acute Ebola virus disease. Am J Pathol 2018, 188:550-558

37. Honko AN, Johnson JC, Marchand JS, Huzella L, Adams RD, Oberlander N, Torzewski LM, Bennett RS, Hensley LE, Jahrling PB, Olinger GG: High dose sertraline monotherapy fails to protect rhesus macaques from lethal challenge with Ebola virus Makona. Sci Rep 2017, 7:5886

38. Logue J, Vargas Licona W, Cooper TK, Reeder B, Byrum R, Qin J, Deiuliis Murphy N, Cong Y, Bonilla A, Sword J, Weaver W, Kocher G, Olinger GG, Jahrling PB, Hensley LE, Bennett RS: Ebola virus isolation using Huh-7 cells has methodological advantages and similar sensitivity to isolation using other cell types and suckling BALB/c laboratory mice. Viruses 2019, 11

39. Diallo B, Sissoko D, Loman NJ, Bah HA, Bah H, Worrell MC, Conde LS, Sacko R, Mesfin S, Loua A, Kalonda JK, Erondu NA, Dahl BA, Handrick S, Goodfellow I, Meredith LW, Cotten M, Jah U, Guetiya Wadoum RE, Rollin P, Magassouba N, Malvy D, Anglaret X, Carroll MW, Aylward RB, Djingarey MH, Diarra A, Formenty P, Keita S, Gunther S, Rambaut A, Duraffour S: Resurgence of Ebola virus disease in Guinea linked to a survivor with virus persistence in seminal fluid for more than 500 days. Clin Infect Dis 2016, 63:1353-1356

40. Martini GA, Schmidt HA: [Spermatogenic transmission of the "Marburg virus". (Causes of "Marburg simian disease")] German. Klin Wochenschr 1968, 46:398-400

41. Varkey JB, Shantha JG, Crozier I, Kraft CS, Lyon GM, Mehta AK, Kumar G, Smith JR, Kainulainen MH, Whitmer S, Stroher U, Uyeki TM, Ribner BS, Yeh S: Persistence of Ebola virus in ocular fluid during convalescence. N Engl J Med 2015, 372:2423-2427

42. Zeng X, Blancett CD, Koistinen KA, Schellhase CW, Bearss JJ, Radoshitzky SR, Honnold SP, Chance TB, Warren TK, Froude JW, Cashman KA, Dye JM, Bavari S, Palacios G, Kuhn JH, Sun MG: 
Identification and pathological characterization of persistent asymptomatic Ebola virus infection in rhesus monkeys. Nat Microbiol 2017, 2:17113

43. Coffin KM, Liu J, Warren TK, Blancett CD, Kuehl KA, Nichols DK, Bearss JJ, Schellhase CW, Retterer CJ, Weidner JM, Radoshitzky SR, Brannan JM, Cardile AP, Dye JM, Palacios G, Sun MG, Kuhn JH, Bavari S, Zeng X: Persistent Marburg virus infection in the testes of nonhuman primate survivors. Cell Host Microbe 2018, 24:405-416. e3

44. Hirsch AJ, Smith JL, Haese NN, Broeckel RM, Parkins CJ, Kreklywich C, DeFilippis VR, Denton M, Smith PP, Messer WB, Colgin LM, Ducore RM, Grigsby PL, Hennebold JD, Swanson T, Legasse AW, Axthelm MK, MacAllister R, Wiley CA, Nelson JA, Streblow DN: Zika virus infection of rhesus macaques leads to viral persistence in multiple tissues. PLoS Pathog 2017, 13:e1006219

45. Labadie K, Larcher T, Joubert C, Mannioui A, Delache B, Brochard P, Guigand L, Dubreil L, Lebon P, Verrier B, de Lamballerie X, Suhrbier A, Cherel Y, Le Grand R, Roques P: Chikungunya disease in nonhuman primates involves long-term viral persistence in macrophages. J Clin Invest 2010, 120:894-906

46. Chantler JK, Tingle AJ, Petty RE: Persistent rubella virus infection associated with chronic arthritis in children. N Engl J Med 1985, 313: 1117-1123

47. Yrjanainen H, Hytonen J, Hartiala P, Oksi J, Viljanen MK: Persistence of borrelial DNA in the joints of borrelia burgdorferi-infected mice after ceftriaxone treatment. APMIS 2010, 118:665-673

48. Levick JR: Microvascular architecture and exchange in synovial joints. Microcirculation 1995, 2:217-233

49. Runowska M, Majewski D, Niklas K, Puszczewicz M: Chikungunya virus: a rheumatologist's perspective. Clin Exp Rheumatol 2018, 36: 494-501

50. Webb RH, Grant C, Harnden A: Acute rheumatic fever. BMJ 2015, 351:h3443

51. Fausther-Bovendo H, Qiu X, McCorrister S, Westmacott G, Sandstrom P, Castilletti C, Di Caro A, Ippolito G, Kobinger GP: Ebola virus infection induces autoimmunity against dsDNA and HSP60. Sci Rep 2017, 7:42147

52. Tozay S, Fischer WA, Wohl DA, Kilpatrick K, Zou F, Reeves E, Pewu K, DeMarco J, Loftis AJ, King K, Grant D, Schieffelin J, Gorvego G, Johnson H, Conneh T, Williams G, Nelson JAE, Hoover D, McMillian D, Merenbloom C, Hawks D, Dube K, Brown J: Long-term complications of Ebola virus disease: prevalence and predictors of major symptoms and the role of inflammation. Clin Infect Dis 2019 [Epub ahead of print] doi:10.1093/cid/ciz1062

53. Huttner A, Siegrist CA: Durability of single-dose rVSV-ZEBOV vaccine responses: what do we know? Expert Rev Vaccin 2018, 17: 1105-1110

54. Samai M, Seward JF, Goldstein ST, Mahon BE, Lisk DR, Widdowson MA, Jalloh MI, Schrag SJ, Idriss A, Carter RJ, Dawson P, Kargbo SAS, Leigh B, Bawoh M, Legardy-Williams J, Deen G, Carr W, Callis A, Lindblad R, Russell JBW, Petrie CR, Fombah AE, Kargbo B, McDonald W, Jarrett OD, Walker RE, Gargiullo P, BashTaqi D, Gibson L, Fofanah AB, Schuchat A, Team SS: The Sierra Leone trial to introduce a vaccine against Ebola: an evaluation of rVSVG-ZEBOV-GP vaccine tolerability and safety during the West Africa Ebola outbreak. J Infect Dis 2018, 217:S6-S15

55. Finckh A, Yerly S, Dayer J-A, Huttner A, Lazarou I, Fabreguet I, Berner J, Tapparel L, Kaiser L, Gabay C, Siegrist C-A: THU0245 post-vaccinal arthritis in an Ebola vaccine trial with a live-attenuated recombinant virus expressing the Ebola surface glycoprotein (RVSVZEBOV). Ann Rheum Dis 2015, 74:286

56. Halperin SA, Arribas JR, Rupp R, Andrews CP, Chu L, Das R, Simon JK, Onorato MT, Liu K, Martin J, Helmond FA, Team VS: Six-month safety data of recombinant vesicular stomatitis Virus-Zaire Ebola virus envelope glycoprotein vaccine in a phase 3 double-blind, placebo-controlled randomized study in healthy adults. J Infect Dis 2017, 215:1789-1798

57. Huttner A, Agnandji ST, Combescure C, Fernandes JF, Bache EB, Kabwende L, Ndungu FM, Brosnahan J, Monath TP, Lemaitre B, Grillet S, Botto M, Engler O, Portmann J, Siegrist D, Bejon P, Silvera P, Kremsner P, Siegrist CA; VEBCON, VSV-EBOVAC, VSV-EBOPLUS Consortia: Determinants of antibody persistence across doses and continents after single-dose rVSV-ZEBOV vaccination for Ebola virus disease: an observational cohort study. Lancet Infect Dis 2018, 18:738-748

58. Davis C, Tipton T, Sabir S, Aitken C, Bennett S, Becker S, Evans T, Fehling SK, Gunson R, Hall Y, Jackson C, Johanssen I, Kieny MP, McMenamin J, Spence E, Strecker T, Sykes C, Templeton K, Thorburn F, Peters E, Henao Restrepo AM, White B, Zambon M, Carroll MW, Thomson EC: Post-exposure prophylaxis with rVSVZEBOV following exposure to a patient with Ebola virus disease relapse in the UK: an operational, safety and immunogenicity report. Clin Infect Dis 2019 [Epub ahead of print] doi:10.1093/cid/ciz1165 